\title{
Electrocardiography in a patient with tremulant Parkinson's disease
}

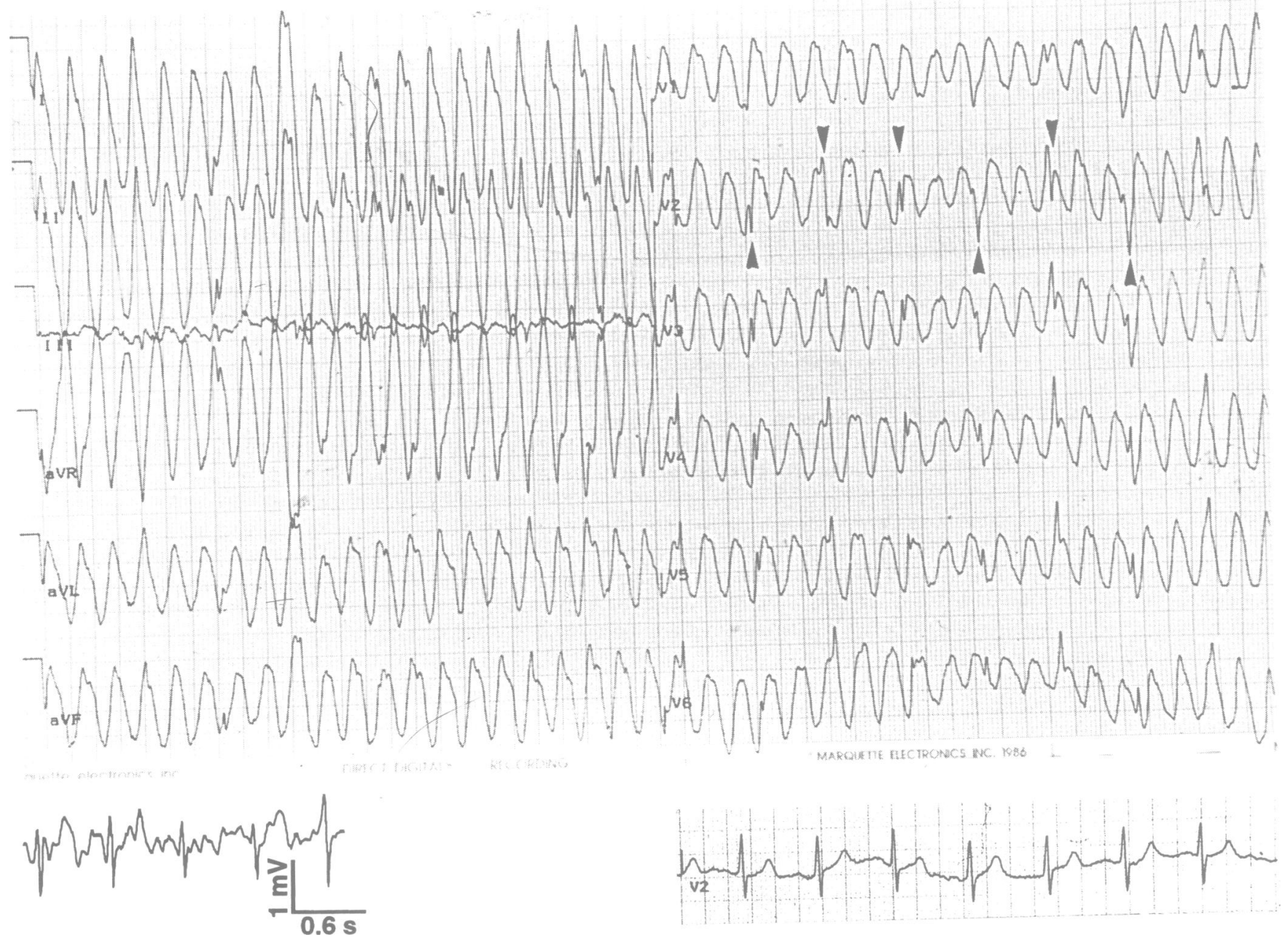

Electrocardiography of an 82 year old patient with tremulant Parkinson's disease recorded on admission to hospital.

Top-A $4 \mathrm{~Hz}$-tremor caused an artifact, which could lead to the erroneous diagnosis of atrial fibrillation in Wolffarkinson-White syndrome or ventricular flutter. A closer look, however, allows identification of the artifact: in lead III the tremor is not visible (tremor amplitude was smallest in the left leg) and the underlying QRS complexes can be recognised (arrowheads in V2).

Below left-Lead V2 was digitised at a sampling frequency of $400 \mathrm{~Hz}$ and filtered to eliminate the $4 \mathrm{~Hz}$ tremor. Underlying QRS complexes are now readily visible and occur at a frequency of $96 \mathrm{bpm}$. The pulse rate of the patient, who did not show any sign of cardiac distress, was $96 \mathrm{bpm}$.

Below right-After 10 days of treatment with amantadine and levodopa tremor had almost disappeared and the ECG showed normal sinus rhythm (Lead V2)

CHR LÜSCHER 